\title{
Effect of statin treatment on vasospasm-related morbidity and functional outcome in patients with aneurysmal subarachnoid hemorrhage: a systematic review and meta-analysis
}

\author{
*Jian Shen, MD, Kai-Yuan Huang, MD, Yu Zhu, MD, Jian-Wei Pan, MD, PhD, Hao Jiang, MD, \\ Yu-Xiang Weng, MD, and Ren-Ya Zhan, MD, PhD
}

Department of Neurosurgery, First Affiliated Hospital, School of Medicine, Zhejiang University, Hangzhou City, Zhejiang Province, People's Republic of China

OBJECTIVE The efficacy of statin therapy in treating aneurysmal subarachnoid hemorrhage (SAH) remains controversial. In this meta-analysis, the authors investigated whether statin treatment significantly reduced the incidence of cerebral vasospasm and delayed neurological deficits, promoting a better outcome after aneurysmal SAH.

METHODS A literature search of the PubMed, Ovid, and Cochrane Library databases was performed for randomized controlled trials (RCTs) and prospective cohort studies investigating the effect of statin treatment. The end points of cerebral vasospasm, delayed ischemic neurological deficit (DIND), delayed cerebral infarction, mortality, and favorable outcome were statistically analyzed.

RESULTS Six RCTs and 2 prospective cohort studies met the eligibility criteria, and a total of 1461 patients were included. The meta-analysis demonstrated a significant decrease in the incidence of cerebral vasospasm (relative risk $[R R]$ 0.76, 95\% confidence interval [Cl] 0.61-0.96) in patients treated with statins after aneurysmal SAH. However, no significant benefit was observed for DIND (RR 0.88, 95\% Cl 0.70-1.12), delayed cerebral infarction (RR 0.66, 95\% $\mathrm{Cl} 0.33-1.31$ ), mortality (RR $0.69,95 \% \mathrm{Cl} 0.39-1.24$ ) or favorable outcome, according to assessment by the modified Rankin Scale or Glasgow Outcome Scale (RR 0.99, 95\% Cl 0.92-1.17).

CONCLUSIONS Treatment with statins significantly decreased the occurrence of vasospasm after aneurysmal SAH. The incidence of DIND, delayed cerebral infarction, and mortality were not affected by statin treatment. Future research should focus on DIND and how statins influence DIND.

https://thejns.org/doi/abs/10.3171/2016.5.JNS152900

KEY WORDS subarachnoid hemorrhage; vasospasm; delayed ischemic neurological deficit; statin; meta-analysis; aneurysm; vascular disorders

$\mathrm{A}$ NEURYSMAL subarachnoid hemorrhage (SAH) accounts for $3 \%-5 \%$ of all strokes and affects 600,000 patients worldwide per year. ${ }^{35,39}$ It typically affects a younger population than other types of stroke, and its combined morbidity and mortality reaches as high as $50 \%{ }^{1,39}$ Cerebral vasospasm is a common complication occurring 4-14 days after surgery in patients with aneurysmal SAH, and this can lead to severe delayed ischemic neurological deficit (DIND) and delayed cerebral infarction, which are indicative of a poor prognosis..$^{12,14,18,22}$ Therefore, pharmacological treatments have targeted the prevention of cerebral vasospasm, with disappointing results. ${ }^{40}$ Nimodipine is the only drug that has moderately reduced vasospasm and DIND after SAH. ${ }^{25,47}$

Recent studies have identified statin drugs as a potential treatment for vasospasm; multiple vascular functions for statin have been revealed using animal models that might help to reduce vasospasm in patients after aneurysm SAH. $4,8,13,24,28,32$ However, the results from published clinical trials have been controversial. Some Phase II trials found that statin was effective in decreasing the incidence of vasospasm, while others have failed to confirm these

ABBREVIATIONS $\mathrm{Cl}=$ confidence interval; DIND = delayed ischemic neurological deficit; GCS = Glasgow Coma Scale; GOS = Glasgow Outcome Scale; HDS-SAH = High-Dose Simvastatin for Aneurysmal Subarachnoid Hemorrhage; $\mathrm{HHH}=$ hypertension, hypervolemia, and hemodilution; M-H = Mantel-Haenszel; mRS = modified Rankin Scale; RCT = randomized controlled trial; RR = relative risk; SAH = subarachnoid hemorrhage; STASH = Simvastatin in Aneurysmal Subarachnoid Hemorrhage; TCD = transcranial Doppler; WFNS = World Federation of Neurosurgical Societies.

SUBMITTED December 12, 2015. ACCEPTED May 25, 2016.

INCLUDE WHEN CITING Published online October 7, 2016; DOI: 10.3171/2016.5.JNS152900.

* Drs. Shen, Huang, and Zhu contributed equally to this work. 
findings. $5,10,18,37,42,44$ Meta-analyses have also produced inconsistent results. Four studies demonstrated a beneficial effect of statin treatment in at least 1 aspect, ${ }^{33,34,36,48}$ while no benefits were reported by the authors of 3 additional studies. ${ }^{16,17,41}$ Recently, 2 large-scale multicenter Phase III trials-Simvastatin in Aneurysmal Subarachnoid Hemorrhage (STASH) and High-Dose Simvastatin for Aneurysmal Subarachnoid Hemorrhage (HDS-SAH) - yielded disappointing findings; no benefits of simvastatin treatment were observed in patients with aneurysmal SAH during the STASH study, while authors of the HDS-SAH study reported that treatment with high doses of simvastatin $(80 \mathrm{mg}$ ) was no more effective than treatment with low doses $(40 \mathrm{mg}))^{13,44,47}$ Both studies had limitations; no details of vasospasm were described in the STASH study, and no control group was used in the HDS-SAH study, making it difficult to draw firm conclusions. ${ }^{17}$ Therefore, the effect of statins on vasospasm remains unclear; positive effects may have been neutralized through an adverse pathway. Alternatively, statins may not be effective in humans. These questions currently remain unanswered.

Recently, a prospective cohort trial was published that investigated cognitive outcome after acute simvastatin treatment..$^{45}$ The observation period was not longer than 3 months; therefore, this type of study, with matched baseline characteristics and no loss to follow-up, may prove more useful than some small-scale randomized controlled trials (RCTs). A large-scale meta-analysis including RCTs and prospective cohort studies might reveal better evidence of the medical efficacy of statins in treating patients with aneurysmal SAH.

\section{Methods}

\section{Search Strategy}

We performed a literature search of the PubMed, Ovid, and Cochrane Library databases in November 2015. Additionally, we screened the US NIH clinicaltrials.gov database to identify ongoing clinical trials. The following search terms were used: 1) "statin" and "statin*" and "\$statin"; 2) "aneurysmal subarachnoid hemorrhage" and "subarachnoid h*emorrhage" and "subarachnoid hemorrhage." We restricted the search to human studies, without any language limitations. All search results, including review articles, were evaluated by 2 investigators (J.W.P. and H.J.). Finally, the authors of the studies included in this meta-analysis were contacted to obtain any unpublished data related to the subject of our analysis.

Two investigators (J.W.P. and H.J.) independently selected potentially appropriate trials from the retrieved literature according to our inclusion criteria. The initial selection was based on a review of the title and abstract, and in a second selection the investigators reviewed the text in full. A consensus on which studies to include was established after a discussion between the investigators.

\section{Eligibility Criteria}

The following inclusion criteria were applied: 1) RCTs or prospective cohort studies investigated the effects of acute statin therapy in treating SAH; 2) patients were all diagnosed with aneurysmal SAH; 3) studies included at least 1 of the following end points: cerebral vasospasm, DIND, delayed cerebral ischemia, outcomes measurements, and mortality.

The following exclusion criteria were applied: 1) the efficacy of statin treatment not investigated in human participants (such as experimental investigation and animal studies); 2) unmatched patient baseline characteristics between groups; 3) statin treatment of SAH not caused by ruptured aneurysm (such as trauma and arteriovenous malformation rupture); 4) statin treatment investigated prior to SAH or investigation into long-term use of statins; and 5) comparison of statin treatment with other drugs (such as magnesium sulfate and nimodipine).

\section{Data Extraction}

Data were extracted independently by 2 investigators (J.W.P. and H.J.), and a consensus was established. The following information was extracted from each publication: journal name, year of publication, first author, demographic information, baseline demographic and clinical characteristics, inclusion and exclusion criteria, interventions, and number of end points per subgroup. No unpublished data were received from the authors of the included studies.

\section{Study End Points}

The primary end point was cerebral vasospasm, and the secondary end points included DIND, delayed cerebral infarction, favorable outcomes, and mortality. The end points were defined according to the original studies (Table 1).

\section{Statistical Analysis}

Relative risks (RRs) and 95\% confidence intervals (CIs) were calculated from the number of outcome events per subgroup to estimate the association of statin administration with various end point events. The heterogeneity of the study results was assessed by Cochran $\chi^{2} \mathrm{Q}$ statistics and the $\mathrm{I}^{2}$ test, which determined whether the fixed-effects Mantel-Haenszel (M-H) or random-effects DerSimonian and Laird model was used. A p value $\leq 0.1$ or $^{2}$ value $\geq 50 \%$ was considered indicative of heterogeneity. Sensitivity analyses were conducted to assess the influence of specific studies on the combined effect. All tests were 2 -sided, and a $\mathrm{p}$ value $\leq 0.05$ was considered significant. Statistical analyses were performed with Review Manager 5.3 and the Stata statistical software package (release 14.0; Stata Corp.).

\section{Methodological Quality Assessment}

Two investigators (J.W.P. and Y.X.W.) independently evaluated the methodological quality of the included trials with the Cochrane Collaboration's tool for assessing risk of bias, and a consensus was established.

\section{Results}

\section{Search Results}

One hundred sixteen studies were retrieved from PubMed, 57 from Ovid, 72 from the Cochrane Library, and 8 clinical trials were retrieved from the clinicaltrials. gov database. Duplicate studies and studies that did not 
TABLE 1. Characteristics of patients with aneurysmal SAH in the 6 RCTs and 2 prospective cohort studies

\begin{tabular}{|c|c|c|c|c|c|c|c|c|}
\hline $\begin{array}{l}\text { Authors } \\
\& \text { Year }\end{array}$ & $\begin{array}{l}\text { Study } \\
\text { Type }\end{array}$ & $\begin{array}{l}\text { Statin/ } \\
\text { Placebo (no. } \\
\text { of patients) }\end{array}$ & $\begin{array}{l}\text { Mean } \\
\text { Age (yrs } \\
\pm \text { SD) }\end{array}$ & $\begin{array}{c}\text { Female } \\
(\%)\end{array}$ & $\begin{array}{l}\text { WFNS Grade } \\
\geq \text { IV (statin/ } \\
\text { placebo, total) }\end{array}$ & $\begin{array}{l}\text { Fisher } \\
\text { Grade } \\
\geq \mathrm{IV}(\%)\end{array}$ & $\begin{array}{l}\text { Clipping } \\
(\%)\end{array}$ & Intervention \\
\hline $\begin{array}{l}\text { Lynch et al., } \\
\qquad 2015\end{array}$ & $\mathrm{RCT}$ & $19 / 20$ & $56 \pm 15$ & $33(85)$ & & $2(5)$ & $17(44)$ & $\begin{array}{l}\text { Patients randomized w/in } 48 \mathrm{hrs} \text { of symptom } \\
\text { onset to receive either } 80 \mathrm{mg} \text { simvastatin daily } \\
\text { or placebo for } 14 \text { days }\end{array}$ \\
\hline $\begin{array}{l}\text { Tseng et al., } \\
2005\end{array}$ & RCT & $40 / 40$ & $53 \pm 12$ & $44(55)$ & 13/13, $26(33 \%)$ & & $52(65)$ & $\begin{array}{l}\text { Patients w/in } 72 \text { hrs from ictus were randomized } \\
\text { equally to receive either } 40 \text { mg oral pravas- } \\
\text { tatin or placebo daily for up to } 14 \text { days }\end{array}$ \\
\hline $\begin{array}{l}\text { Chou et al., } \\
2008\end{array}$ & RCT & $19 / 20$ & $53 \pm 13$ & $29(74)$ & $5 / 4,9(23 \%)$ & $0(0)$ & $33(85)$ & $\begin{array}{l}\text { Thirty-nine statin-naïve Fisher Grade } 3 \mathrm{SAH} \\
\text { patients were double-blind randomized to } \\
\text { receive simvastatin } 80 \mathrm{mg} / \text { day or placebo }\end{array}$ \\
\hline $\begin{array}{r}\text { Macedo et } \\
\text { al., } 2010\end{array}$ & $\begin{array}{l}\text { RCT, } \\
\text { no } \\
\text { blind }\end{array}$ & $11 / 9$ & & & & $8(38)$ & & $\begin{array}{l}\text { Prospective, randomized, nonblind studies, } 80 \\
\text { mg simvastatin daily w/in } 72 \text { hrs of ictus \& a } \\
\text { control group not used for } 21 \text { days }\end{array}$ \\
\hline $\begin{array}{l}\text { Garg et al., } \\
2013\end{array}$ & RCT & $19 / 19$ & $49 \pm 9$ & $17(45)$ & $1 / 0,1(3 \%)$ & $0(0)$ & $38(100)$ & $\begin{array}{l}\text { All patients w/ aneurysmal SAH admitted w/in } \\
96 \mathrm{hrs} \text { of ictus randomized to receive either } \\
\text { simvastatin or placebo } 80 \mathrm{mg} / \text { day for } 14 \text { days }\end{array}$ \\
\hline $\begin{array}{l}\text { Kirkpatrick et } \\
\text { al., } 2014\end{array}$ & RCT & $391 / 412$ & $50 \pm 10$ & $551(69)$ & $95 / 89,184(23 \%)$ & $406(51)$ & $256(32)$ & $\begin{array}{l}\text { Patients randomly assigned (1:1) to receive either } \\
\text { simvastatin } 40 \mathrm{mg} \text { or placebo daily for } 21 \text { days }\end{array}$ \\
\hline $\begin{array}{l}\text { McGirt et al., } \\
2009\end{array}$ & Psp & $170 / 170$ & $53 \pm 13$ & $256(73)$ & $45 / 34,79(23 \%)$ & $125(37)$ & $275(81)$ & $\begin{array}{l}80 \text { mg simvastatin per day from admission until } \\
\text { at least } 14 \text { days compared w/ control group } \\
\text { w/o simvastatin treatment }\end{array}$ \\
\hline $\begin{array}{l}\text { Wong et al., } \\
2015\end{array}$ & Psp & $51 / 51$ & $57 \pm 10$ & $74(73)$ & $6 / 6,12(12 \%)$ & & $42(41)$ & $\begin{array}{l}\text { HDS-SAH patients randomly assigned to receive } \\
\text { either } 80 \text { mg or } 40 \text { mg of simvastatin daily for } \\
3 \text { wks, w/ matched patients w/o simvastatin } \\
\text { treatment in CD-SAH study }\end{array}$ \\
\hline
\end{tabular}

$\mathrm{CD}-\mathrm{SAH}=$ Cognitive Dysfunction after Aneurysmal Subarachnoid Hemorrhage; $\mathrm{Psp}=$ prospective cohort studies.

meet the inclusion criteria were excluded. Two RCTs were excluded based on unmatched baseline patient characteristics: 1) Vergouwen et al. 2009, in which there were 44\% of patients (7/16) in the simvastatin group and 6\% of patients $(1 / 16)$ in the placebo group, with a World Federation of Neurosurgical Societies (WFNS) score $\geq 4(\mathrm{p}=0.00$, Fisher's exact test); and 2) Diringer et al. 2014, in which there were $13 \%$ of patients in the simvastatin group and $42 \%$ of patients in the placebo group, with a WFNS score of 3-5.,42 Six RCTs and 2 prospective studies qualified for the meta-analysis. ${ }^{5,10,13,18,21,23,37,45}$ A flowchart of the literature search for eligible articles is shown in Fig. 1.

\section{Characteristics of Eligible Studies}

The characteristics of the included studies are listed in Table 1. The eligibility criteria for patients recruited were similar between the trials. A total of 1461 patients were included: 1019 patients from 6 RCTs and 442 patients from 2 prospective studies. . $^{5,10,13,18,21,37,42,45}$ Four hundred ninety-nine patients received statin treatment and 520 patients received placebo treatment in 6 RCTs. Two hundred twenty-one patients received statin treatment and 221 patients received placebo treatment in 2 prospective studies. Baseline characteristics were described in detail, except in 1 study. ${ }^{21}$ Seventy percent of the patients were female (1004/1441). WFNS or Hunt and Hess grades were described in all studies except 2. ${ }^{18,21}$ Twenty-two percent of patients (311/1402) were in an initial comatose state (WFNS Grade $\geq 4$ ). The Fisher grade was provided in 6 studies, and $43 \%$ of patients (541/1252) were Fisher

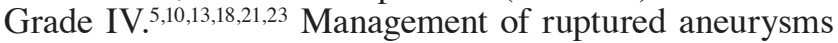
was described in all except 1 study, and $49 \%$ of patients (713/1441) underwent microsurgical clipping. ${ }^{21}$ Patient characteristics with a potential effect on the outcomes were similar between the simvastatin and placebo groups. Details of administered treatments, including nimodipine and fluid therapy, were described in all studies.

\section{Definitions of Study End Points}

Definitions and results of the study end points are presented in Table 2. Vasospasm was defined in multiple ways in some studies; we analyzed the transcranial Doppler (TCD) cerebral artery velocity in this meta-analysis. Four studies used TCD cerebral artery velocity to detect vasospasm, and these velocities varied..$^{5,10,18,37}$ In the studies by McGirt et al. and Macedo et al., vasospasm was defined as responding to the combination of induced hypertension, hypervolemia, and hemodilution $(\mathrm{HHH})$ therapy, or angiographic change. ${ }^{21,23}$

Definitions of the secondary end points also varied; new ischemic neurological deficits or a decrease in 2 or more points on the modified Glasgow Coma Scale (GCS) were the criteria of DIND in 5 studies. ${ }^{5,10,13,37,45}$ Delayed cerebral infarction was mainly confirmed by CT, MRI, or other radiological strategies in 4 studies. ${ }^{5,13,37,44}$ Mortality rates were provided in 6 studies, and the Glasgow 


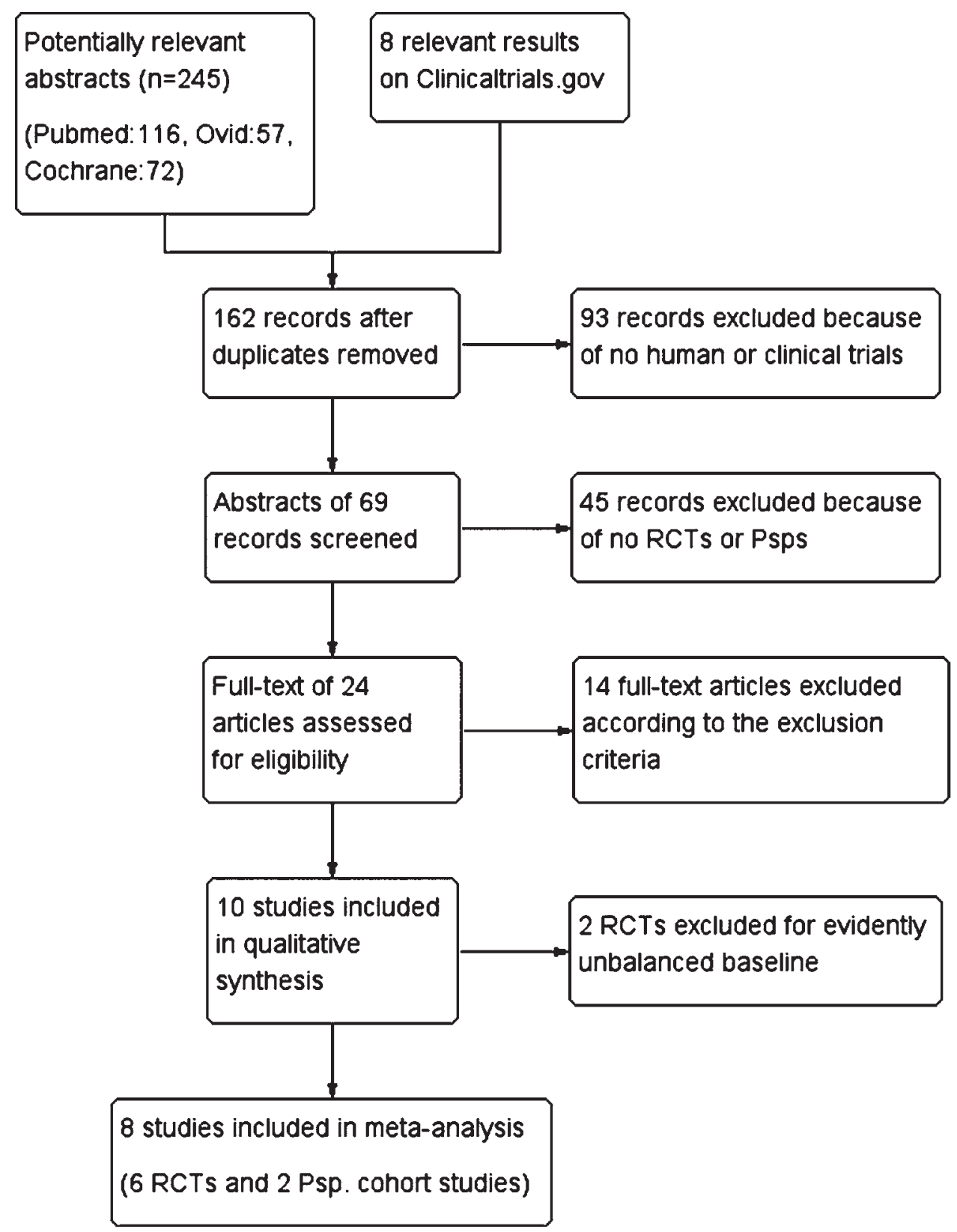

FIG. 1. Flowchart of the literature search procedure. Psps = prospective studies.

Outcome Scale (GOS) and modified Rankin Scale (mRS) scores were assessed in 7 studies..$^{5,10,13,21,22,37,45}$ The time of assessment ranged from hospital discharge to 3-6 months after the ictus. In 2 RCTs, only the median GOS and mRS scores were provided, without the exact patient values for each score. ${ }^{10,21}$ A favorable outcome was defined as an mRS score $\leq 2$ in 4 studies and a GOS score $\geq 3$ in 1 study. $5,13,23,37,45$

\section{Risk of Bias Assessment}

The quality of the included studies was measured by Cochrane risk of bias assessment. If bias was not addressed in the trials, we assumed an unclear risk. The 2 prospective studies showed a high risk for randomization and blinding, while 2 of the small-sample RCTs showed unclear bias risk by failing to describe the WFNS grade. However, these conclusions are subjective (Fig. 2).

\section{Outcomes of Meta-Analysis}

The pooled results are shown in Fig. 3. The incidence of cerebral vasospasm was $29 \%(82 / 278)$ and $39 \%(108 / 278)$ in statin-treated and placebo-treated patients, respectively. The statin-treated group had a lower incidence of cerebral vasospasm (M-H pooled RR 0.76, 95\% CI 0.61-0.96; p $=0.02)$. Analysis of heterogeneity revealed mild heterogeneity among the studies (heterogeneity $\chi^{2}=8.55, \mathrm{I}^{2}=$ $42 \%, \mathrm{p}=0.13)$. Sensitivity analysis revealed that $1 \mathrm{RCT}$ was mainly responsible for the heterogeneity (omitted heterogeneity $\chi^{2}=3.26, \mathrm{I}^{2}=0 \%, \mathrm{p}=0.46$ ), which may be explained by the alternative definition of a vasospasm 
TABLE 2. Definitions and results of the study end points of included trials

\begin{tabular}{|c|c|c|c|c|c|}
\hline $\begin{array}{l}\text { Authors } \\
\& \text { Year }\end{array}$ & Cerebral Vasospasm & DIND & Delayed Cerebral Infarction & Favorable Outcome & Mortality \\
\hline $\begin{array}{l}\text { Lynch } \\
\text { et al., } \\
2005\end{array}$ & $\begin{array}{c}V_{M C A} \geq 160 \mathrm{~cm} / \mathrm{sec} \text { by } \mathrm{TCD} \text { or } \\
\text { angiography; } 5 / 19 \text { statins, } \\
12 / 20 \text { controls }(p=0.03)\end{array}$ & & & & \\
\hline $\begin{array}{l}\text { Tseng } \\
\text { et al., } \\
2005\end{array}$ & $\begin{array}{l}\mathrm{V}_{\mathrm{MCA}} \geq 120 \mathrm{~cm} / \mathrm{sec}, \mathrm{w} / \mathrm{a} \mathrm{LR} \\
3 ; 17 / 40 \text { statins, } 25 / 40 \\
\text { controls }(p=0.01)\end{array}$ & $\begin{array}{l}\text { Development of focal neurological } \\
\text { deficits, a drop in GCS score } \\
\text { by } 2 \text { points; } 2 / 40 \text { statins, } 12 / 40 \\
\text { controls }(p=0.00)\end{array}$ & $\begin{array}{l}\text { New cerebral infarcts on } \\
\text { CT scans; } 2 / 40 \text { statins, } \\
12 / 40 \text { controls }(p=0.00)\end{array}$ & $\begin{array}{l}\text { mRS scores assessed } \\
\text { at discharge, mRS } \\
\leq 2 ; 23 / 40 \text { statins, } \\
19 / 40 \text { controls ( } p \\
=0.71 \text { ) }\end{array}$ & $\begin{array}{l}\text { At discharge; } \\
2 / 40 \text { statins, } \\
8 / 40 \text { controls } \\
(p=0.04)\end{array}$ \\
\hline $\begin{array}{l}\text { Chou et } \\
\text { al., } \\
2008\end{array}$ & $\begin{array}{l}\text { Peak systolic middle cerebral } \\
\text { artery velocity }\left(\mathrm{PSV}_{\text {MCA }}\right) \\
\geq 200 \mathrm{~cm} / \mathrm{sec}, \mathrm{w} / \mathrm{a} \mathrm{LR} \\
3 ; 13 / 19 \text { statins, } 10 / 20 \\
\text { controls }(p=0.24)\end{array}$ & $\begin{array}{l}2 \text { or more point decrease in modi- } \\
\text { fied GCS score, unaccountable } \\
\text { new focal neurological deficit } \\
\text { lasting } 2 \text { hrs; } 7 / 19 \text { statins, } 10 / 20 \\
\text { controls ( } p=0.41 \text { ) }\end{array}$ & $\begin{array}{l}\text { Lesion consistent w/ infarc- } \\
\text { tion on CT or MRI in the } \\
\text { territory of angiographic } \\
\text { or TCD vasospasm; } 2 / 19 \\
\text { statins, } 5 / 20 \text { controls ( } p \\
=0.41 \text { ) }\end{array}$ & $\begin{array}{l}\text { mRS scores at } \\
\text { discharge, } m R S \leq 2 ; \\
7 / 19 \text { statins, } 10 / 20 \\
\text { controls }(p=0.41)\end{array}$ & $\begin{array}{l}\text { At discharge; } 0 / 19 \\
\text { statins, } 3 / 20 \\
\text { controls }(p= \\
0.23)\end{array}$ \\
\hline $\begin{array}{l}\text { Macedo } \\
\text { et al., } \\
2010\end{array}$ & $\begin{array}{l}\text { Cerebral arteriography } \\
\text { examination; } 1 / 11 \text { statins, } \\
4 / 9 \text { controls }\end{array}$ & & & & $\begin{array}{l}\text { At discharge; } 2 / 11 \\
\text { statins, } 6 / 9 \\
\text { controls }\end{array}$ \\
\hline $\begin{array}{l}\text { Garg et } \\
\text { al., } \\
2013\end{array}$ & $\begin{array}{l}\text { TCD velocities }>160 \mathrm{~cm} / \mathrm{sec} \\
3 / 19 \text { statins, } 5 / 19 \text { controls } \\
(p=0.70)\end{array}$ & $\begin{array}{l}\text { New ischemic neurological deficits } \\
\text { in } 1 \text { st } 2 \text { wks after the ictus not } \\
\text { attributable to other causes; } \\
5 / 19 \text { statins, } 8 / 19 \text { controls }(p= \\
0.31 \text { ) }\end{array}$ & & & $\begin{array}{l}\text { At } 6 \text { mos follow- } \\
\text { ing ictus; } 1 / 19 \\
\text { statins, } 3 / 19 \\
\text { controls ( } p \\
\geq 0.05 \text { ) }\end{array}$ \\
\hline $\begin{array}{l}\text { Kirkpat- } \\
\text { rick } \\
\text { et al., } \\
2014\end{array}$ & & $\begin{array}{l}\text { A deterioration of } 2 \text { or more points } \\
\text { on the GCS score that could not } \\
\text { be attributed to any other cause; } \\
64 / 391 \text { statins, } 67 / 412 \text { controls } \\
(p=0.97)\end{array}$ & $\begin{array}{l}\text { Proven radiological infarct; } \\
61 / 391 \text { statins, } 71 / 412 \\
\text { controls }(p=0.53)\end{array}$ & $\begin{array}{l}\text { mRS scores assessed } \\
\text { at discharge, mRS } \\
\leq 2 ; 233 / 391 \text { statins, } \\
251 / 412 \text { controls }(p \\
=0.61 \text { ) }\end{array}$ & $\begin{array}{l}\text { At } 6 \text { mos fol- } \\
\text { lowing ictus; } \\
37 / 391 \text { statins, } \\
35 / 412 \text { controls } \\
(p=0.59)\end{array}$ \\
\hline $\begin{array}{l}\text { McGirt } \\
\text { et al., } \\
2009\end{array}$ & $\begin{array}{l}\text { Responding to therapy, a } \\
\text { delayed infarct on CT or } \\
\text { angiographic vasospasm; } \\
43 / 170 \text { statins, } 52 / 170 \\
\text { controls }(p=0.28)\end{array}$ & & & $\begin{array}{l}\text { GOS scores assessed } \\
\text { at discharge, GOS } \\
\geq 3 ; 133 / 170 \text { statins, } \\
139 / 170 \text { controls ( } p \\
=0.42 \text { ) }\end{array}$ & $\begin{array}{l}\text { At discharge; } \\
31 / 170 \text { statins, } \\
26 / 170 \text { controls } \\
(p=0.47)\end{array}$ \\
\hline $\begin{array}{l}\text { Wong } \\
\text { et al., } \\
2015\end{array}$ & & $\begin{array}{l}\text { A fall of } 2 \text { or more points on the } \\
\text { modified GCS, new focal } \\
\text { neurological deficit lasting more } \\
\text { than } 2 \text { hrs, CT evidence; } 20 / 51 \\
\text { statins, } 18 / 51 \text { controls ( } p=0.67 \text { ) }\end{array}$ & $\begin{array}{l}\text { Confirmed by interval CT of } \\
\text { brain; } 8 / 51 \text { statins, } 7 / 51 \\
\text { controls }(p=0.78)\end{array}$ & $\begin{array}{l}\text { mRS scores assessed } \\
\text { at } 3 \text { mos, mRS } \\
\text { score } \leq 2 ; 43 / 51 \\
\text { statins, } 36 / 51 \text { con- } \\
\text { trols }(p=0.10)\end{array}$ & \\
\hline Total & $\begin{array}{l}82 / 278 \text { statins, } 108 / 278 \\
\text { controls }\end{array}$ & $98 / 520$ statins, $115 / 542$ controls & $\begin{array}{l}\text { 73/501 statins, } 95 / 523 \\
\text { controls }\end{array}$ & $\begin{array}{l}\text { 439/671 statins, } \\
455 / 693 \text { controls }\end{array}$ & $\begin{array}{l}\text { 73/650 statins, } \\
81 / 670 \text { controls }\end{array}$ \\
\hline
\end{tabular}

$\mathrm{LR}=\mathrm{Lindegaard}$ ratio; $\mathrm{V}_{\mathrm{MCA}}=$ velocity of the middle cerebral artery.

(peak systolic middle cerebral artery velocity $\geq 200 \mathrm{~cm} /$ sec; omitted M-H pooled RR 0.70, 95\% CI 0.55-0.90, p $=0.01)^{5}$

DIND was observed in 19\% (98/520) of statin-treated patients and 21\% (115/542) of placebo-treated patients, with no statistically significant difference between the 2 groups (M-H pooled RR $0.88,95 \%$ CI $0.70-1.12, \mathrm{p}=0.31$ ). The heterogeneity of DIND was mild (heterogeneity $\chi^{2}=$ $\left.7.45, \mathrm{I}^{2}=46 \%, \mathrm{p}=0.11\right)$. Sensitivity analysis revealed that heterogeneity of DIND was significantly reduced by eliminating the pravastatin study (omitted heterogeneity $\chi^{2}=$ $1.75, \mathrm{I}^{2}=0 \%, \mathrm{p}=0.63$ ), while the RR was not significantly affected (omitted M-H pooled RR 0.97, 95\% CI 0.76-1.24, $\mathrm{p}=0.80) \cdot{ }^{37}$
Delayed cerebral infarction did not differ significantly between statin-treated and placebo-treated patients (statintreated 15\% [73/501], placebo-treated 18\% [95/523], M-H pooled RR 0.66, 95\% CI 0.33-1.31, $\mathrm{p}=0.24$ ). There was moderate heterogeneity in the occurrence of delayed cerebral infarction among the studies (heterogeneity $\chi^{2}=6.44$, $\left.\mathrm{I}^{2}=53 \%, \mathrm{p}=0.09\right)$, and sensitivity analysis showed that the pravastatin study significantly enhanced heterogeneity (omitted heterogeneity $\chi^{2}=1.22, \mathrm{I}^{2}=0 \%, \mathrm{p}=0.54$ ), while the RR was not affected (omitted M-H pooled RR 0.90, $95 \%$ CI $0.67-1.20, \mathrm{p}=0.46){ }^{37}$

Favorable outcome was measured by mRS score in 4 studies and by GOS score in 1 study., $, 13,23,37,45$ There was no significant difference in the number of patients with 


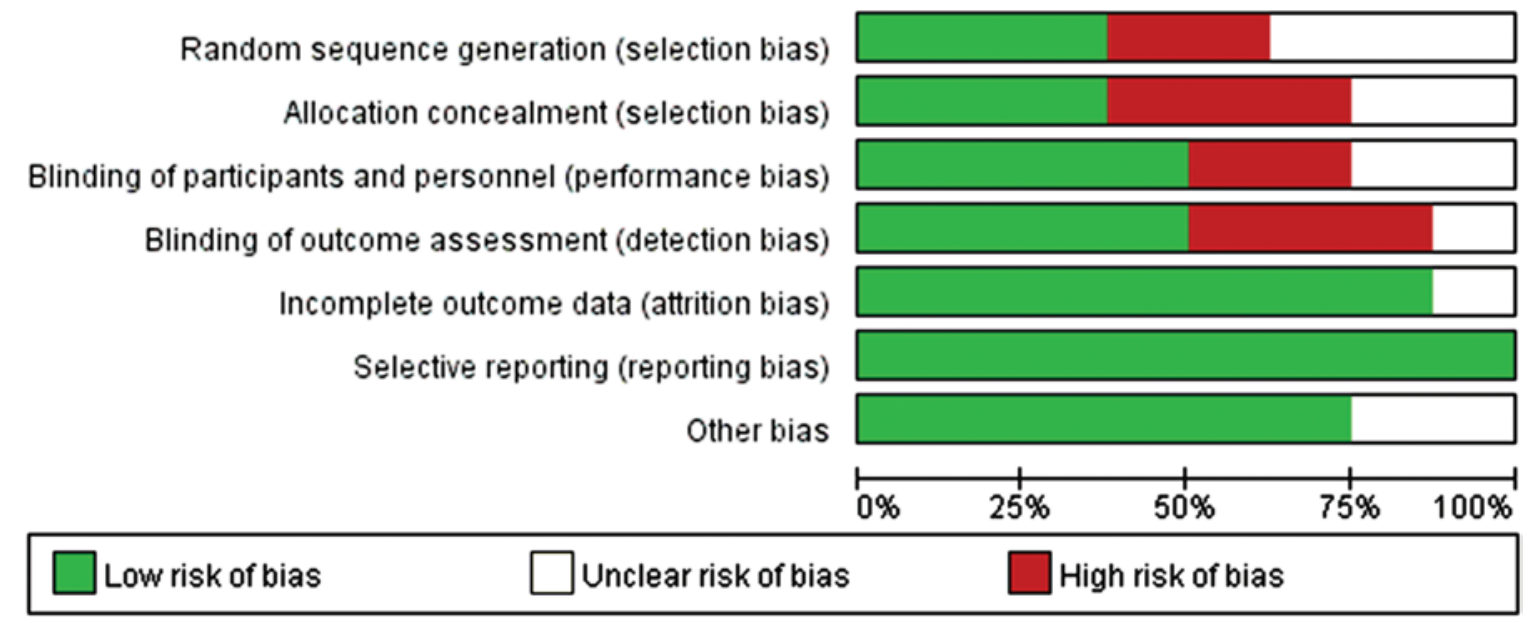

FIG. 2. Quality of the included RCTs and prospective cohort studies assessed by Cochrane risk of bias assessment. Figure is available in color online only.

a favorable outcome between statin-treated and placebotreated groups (statin-treated 65\% [439/671], placebotreated 66\% [455/693], M-H pooled RR 0.99 , 95\% CI $0.92-1.07, \mathrm{p}=0.87)$. There was no heterogeneity in the number of patients having a favorable outcome among the studies (heterogeneity $\chi^{2}=4.91, \mathrm{I}^{2}=19 \%, \mathrm{p}=0.30$ ), and sensitivity analysis revealed that the exclusion of any study did not significantly influence the RR estimate. There was also no significant difference in the overall mortality rate between the statin-treated and placebo-treated groups (statin-treated 11\% [73/650], placebo-treated 12\% [81/670], M-H pooled RR $0.69,95 \%$ CI $0.39-1.24, \mathrm{p}=0.22$ ), and no heterogeneity in the mortality rate was observed between the studies (heterogeneity $\chi^{2}=10.36, \mathrm{I}^{2}=52 \%, \mathrm{p}=0.07$ ). Sensitivity analysis revealed that the RR estimate and heterogeneity were not affected by the exclusion of any study (Table 3).

\section{Meta-Analysis of Subgroups}

We included 2 prospective cohort studies and 6 RCTs, which may have enhanced the potential clinical heterogeneity. ${ }^{23,45}$ One RCT used pravastatin (a hydrophilic statin) while the others used simvastatin (a lipophilic statin). Additionally, to measure patient outcome, some studies used mRS score while others used GOS score. To address this heterogeneity, we conducted subgroup meta-analyses (Table 4).

There was moderate heterogeneity in vasospasm analysis among the RCTs (heterogeneity $\chi^{2}=8.72, \mathrm{I}^{2}=54 \%, \mathrm{p}=$ 0.07 ), which was not significant according to the random method (random M-H pooled RR 0.70, 95\% CI 0.42-1.18; $\mathrm{p}=0.18$ ) on a small-scale analysis of 216 patients. $5,10,18,21,37$ The occurrence of DIND, delayed cerebral infarction, favorable outcome, and death were not significantly different between RCTs and prospective cohort studies. The incidence of cerebral vasospasm was not significantly altered by simvastatin treatment (random $\mathrm{M}-\mathrm{H}$ pooled RR 0.77 , $95 \%$ CI $0.48-1.23, \mathrm{p}=0.27$ ), and the level of heterogeneity was moderate (heterogeneity $\chi^{2}=7.97, \mathrm{I}^{2}=50 \%, \mathrm{p}=$ $0.09) .5,10,13,18,21,23$ No significant difference was observed in the incidence of other outcomes in the simvastatin-treated subgroup analysis. Pravastatin treatment appears to reduce the incidence of DIND and delayed cerebral infarction according to the study by Tseng et al. ${ }^{37}$ Omission of this study reduced the heterogeneity of the DIND and delayed cerebral infarction analysis. A similar effect was observed on the favorable outcomes measured by the mRS and GOS.

\section{Discussion}

The ongoing publication of new clinical trials and different eligibility criteria can make the results from previous meta-analyses controversial. Most previous metaanalyses have only included RCTs with a small number of patients $(\leq 40)$, which were likely to have mismatched patient characteristics between the statin-treated and control groups. This represents a potential source of bias for previous meta-analyses. The patients' baseline characteristics should be carefully considered, especially when evaluating characteristics that have a great impact on the clinical end points. To our knowledge, patients with aneurysmal SAH and a high WFNS grade (4-5) have a higher incidence of DIND compared with patients with low WFNS grades. ${ }^{6,30}$ Hence, we only included studies with similar WFNS grades in the statin-treated and placebo-treated groups and excluded those studies with mismatched clinical characteristics between groups. Two recently published, large-scale multicenter randomized Phase III trials (STASH and HDS-SAH) have not investigated the relationship between statin treatment and vasospasm. The authors of the HDS-SAH study have recently published another prospective cohort trial that investigated the cognitive outcome following acute simvastatin treatment. ${ }^{45}$ In our opinion, studies with matched baseline characteristics between the groups are preferable to RCTs if they had no loss to follow-up because of a short-term observation period ( $\leq 3$ months). We excluded the retrospective cohort studies from our analysis because they had a larger bias than prospective studies and the study design, population, intervention, and control were variable. ${ }^{17}$

We included 6 RCTs and 2 prospective cohort studies that met our eligibility criteria, to generate a larger scale 


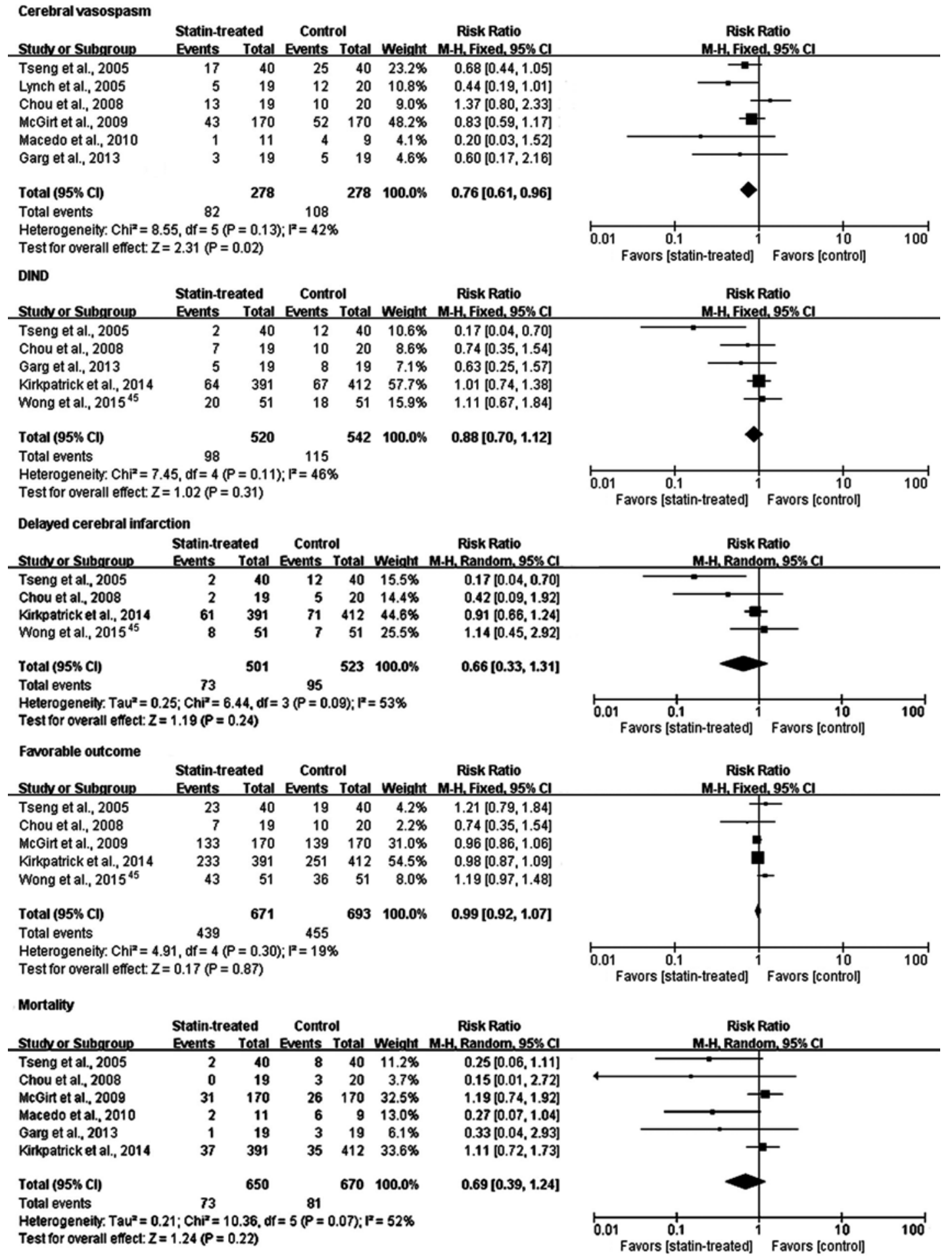

FIG. 3. Forest plots of RRs to measure the efficacy of statin treatment on the prevention of cerebral vasospasm, DIND, delayed cerebral infarction, favorable neurological outcome, and mortality.

meta-analysis, and obtain a more accurate conclusion. Our meta-analysis was also the first to analyze cerebral infarction as an end point, which is difficult to distinguish from severe DIND, especially in comatose or sedated patients. ${ }^{26,43}$ DIND can either be reversible or progress to delayed cerebral infarction, which is often confirmed by an infarction lesion on CT or MRI scan within 6 weeks after
SAH. This is a common cause of unfavorable outcome and death. ${ }^{26}$ After a series of analyses, we found that patients with aneurysmal SAH in the statin-treated groups have a significantly lower incidence of vasospasm. This finding is contradictory to 5 previous meta-studies and consistent with 2 meta-analyses previously published. ${ }^{16,17,33,34,36 \text {, }}$ ${ }_{41,48}$ The results regarding the secondary outcomes were 
TABLE 3. Sensitivity analysis for mortality

\begin{tabular}{lccccccc}
\hline \multicolumn{1}{c}{ Mortality } & $\begin{array}{c}\text { No. of } \\
\text { Patients }\end{array}$ & $\begin{array}{c}\text { No. of } \\
\text { Studies }\end{array}$ & Statins & Placebo & RR (95\% Cl), p Value & $\begin{array}{c}\text { p Value } \\
2^{*}\end{array}$ & \begin{tabular}{c} 
(heterogeneity) $)^{*}$ \\
\hline All trials
\end{tabular} \\
\hline RCTs & 1320 & 6 & $73 / 650$ & $81 / 670$ & $0.69(0.39-1.24), 0.22$ & $52 \%$ & 0.07 \\
\hline Trials w/ simvastatin use & 992 & 5 & $42 / 480$ & $55 / 500$ & $0.44(0.17-1.12), 0.08$ & $55 \%$ & 0.06 \\
\hline High-quality RCTs & 1240 & 5 & $71 / 610$ & $73 / 630$ & $0.99(0.73-1.34), 0.94$ & $43 \%$ & 0.13 \\
\hline Trials informed baseline characteristics & 959 & 4 & $40 / 469$ & $49 / 491$ & $0.50(0.17-1.46), 0.21$ & $51 \%$ & 0.11 \\
\hline
\end{tabular}

${ }^{*}$ An $l^{2}$ value $\geq 50 \%$ or $p$ value $\leq 0.1$ was considered indicative of heterogeneity and a random-effects model was used.

disappointing. We found no evidence that statin treatment can improve DIND or delayed cerebral infarction. We also confirmed that there is no long-term benefit of statin treatment, evaluated by the mRS or GOS.

Previously published meta-analyses are summarized in Table 5. Compared with previous meta-analyses, our study has included the STASH study and imposed stricter eligibility criteria than other reviews, making our results more credible. Additionally, the present study has analyzed a larger number of patients in the meta-analysis (especially of vasospasm) and has a lower heterogeneity and higher power than those previously published. The clustering of all end point results in our study is also a novel finding compared with previous meta-analyses of the same subject.

The reduction in vasospasm did not translate into a measurable clinical benefit according to our analysis. This finding is supported by a recent prospective study comparing the efficacy of different simvastatin doses on cerebral vasospasm. ${ }^{46}$ This finding is very similar to that seen in the studies of clazosentan (the Clazosentan to Overcome Neurological Ischemia and Infarct Occurring After Subarachnoid Hemorrhage [CONSCIOUS] trials), in which vasospasm improvement occurs but functional outcome was

TABLE 4. Subgroup meta-analysis

\begin{tabular}{|c|c|c|c|c|c|c|c|}
\hline Outcomes & No. of Patients & No. of Studies & Statins & Placebo & RR $(95 \%$ Cl), p Value & $2^{2 *}(\%)$ & p Value (heterogeneity) \\
\hline \multicolumn{8}{|l|}{ Cerebral vasospasm } \\
\hline RCTs & 216 & 5 & $39 / 108$ & $56 / 108$ & 0.70 (0.42-1.18), 0.18 & 54 & 0.07 \\
\hline Psps & 340 & 1 & $43 / 170$ & $52 / 170$ & $0.83(0.59-1.17), 0.28$ & & \\
\hline Simvastatin & 476 & 5 & $65 / 238$ & $83 / 238$ & 0.77 (0.48-1.23), 0.27 & 50 & 0.09 \\
\hline Pravastatin & 80 & 1 & $17 / 40$ & $25 / 40$ & $0.68(0.44-1.05), 0.08$ & & \\
\hline \multicolumn{8}{|l|}{ DIND } \\
\hline RCTs & 960 & 4 & $78 / 469$ & $97 / 491$ & 0.68 (0.39-1.19), 0.18 & 55 & 0.08 \\
\hline Psps & 102 & 1 & $20 / 51$ & $18 / 51$ & $1.11(0.67-1.84), 0.68$ & & \\
\hline Simvastatin & 982 & 4 & $96 / 480$ & $103 / 502$ & 0.97 (0.76-1.24), 0.80 & 0 & 0.63 \\
\hline Pravastatin & 80 & 1 & $2 / 40$ & $12 / 40$ & $0.17(0.04-0.70), 0.01$ & & \\
\hline \multicolumn{8}{|c|}{ Delayed cerebral infarction } \\
\hline RCTs & 922 & 3 & $65 / 450$ & $88 / 472$ & 0.48 (0.16-1.40), 0.18 & 67 & 0.05 \\
\hline Psps & 102 & 1 & $8 / 51$ & $7 / 51$ & $1.14(0.45-2.92), 0.78$ & & \\
\hline Simvastatin & 944 & 3 & $71 / 461$ & $83 / 483$ & 0.90 (0.67-1.20), 0.46 & 0 & 0.54 \\
\hline Pravastatin & 80 & 1 & $2 / 40$ & $12 / 40$ & $0.17(0.04-0.70), 0.01$ & & \\
\hline \multicolumn{8}{|l|}{ Favorable outcomes } \\
\hline RCTs & 922 & 3 & $263 / 450$ & $280 / 472$ & 0.99 (0.89-1.10), 0.79 & 0 & 0.46 \\
\hline Psps & 442 & 2 & $176 / 221$ & $175 / 221$ & $1.05(0.85-1.30), 0.67$ & 70 & 0.07 \\
\hline Simvastatin & 1266 & 4 & $416 / 613$ & $436 / 653$ & $0.98(0.91-1.06), 0.68$ & 26 & 0.26 \\
\hline Pravastatin & 80 & 1 & $23 / 40$ & $19 / 40$ & 1.21 (0.79-1.84), 0.37 & & \\
\hline $\mathrm{mRS}$ & 1024 & 4 & $306 / 501$ & $316 / 523$ & 1.01 (0.92-1.11), 0.84 & 27 & 0.25 \\
\hline GOS & 340 & 1 & $133 / 170$ & $139 / 170$ & 0.96 (0.86-1.06), 0.42 & & \\
\hline \multicolumn{8}{|l|}{ Mortality } \\
\hline RCTs & 980 & 5 & $42 / 480$ & $55 / 500$ & $0.44(0.17-1.12), 0.08$ & 55 & 0.06 \\
\hline Psps & 340 & 1 & $31 / 170$ & $26 / 170$ & $1.19(0.74-1.92), 0.47$ & & \\
\hline Simvastatin & 1240 & 5 & $71 / 610$ & $73 / 630$ & $0.99(0.73-1.34), 0.94$ & 43 & 0.13 \\
\hline Pravastatin & 80 & 1 & $2 / 40$ & $8 / 40$ & $0.25(0.06-1.11), 0.07$ & & \\
\hline
\end{tabular}

* An $I^{2}$ value $\geq 50 \%$ or $p$ value $\leq 0.1$ was considered indicative of heterogeneity and a random-effects model was used. 


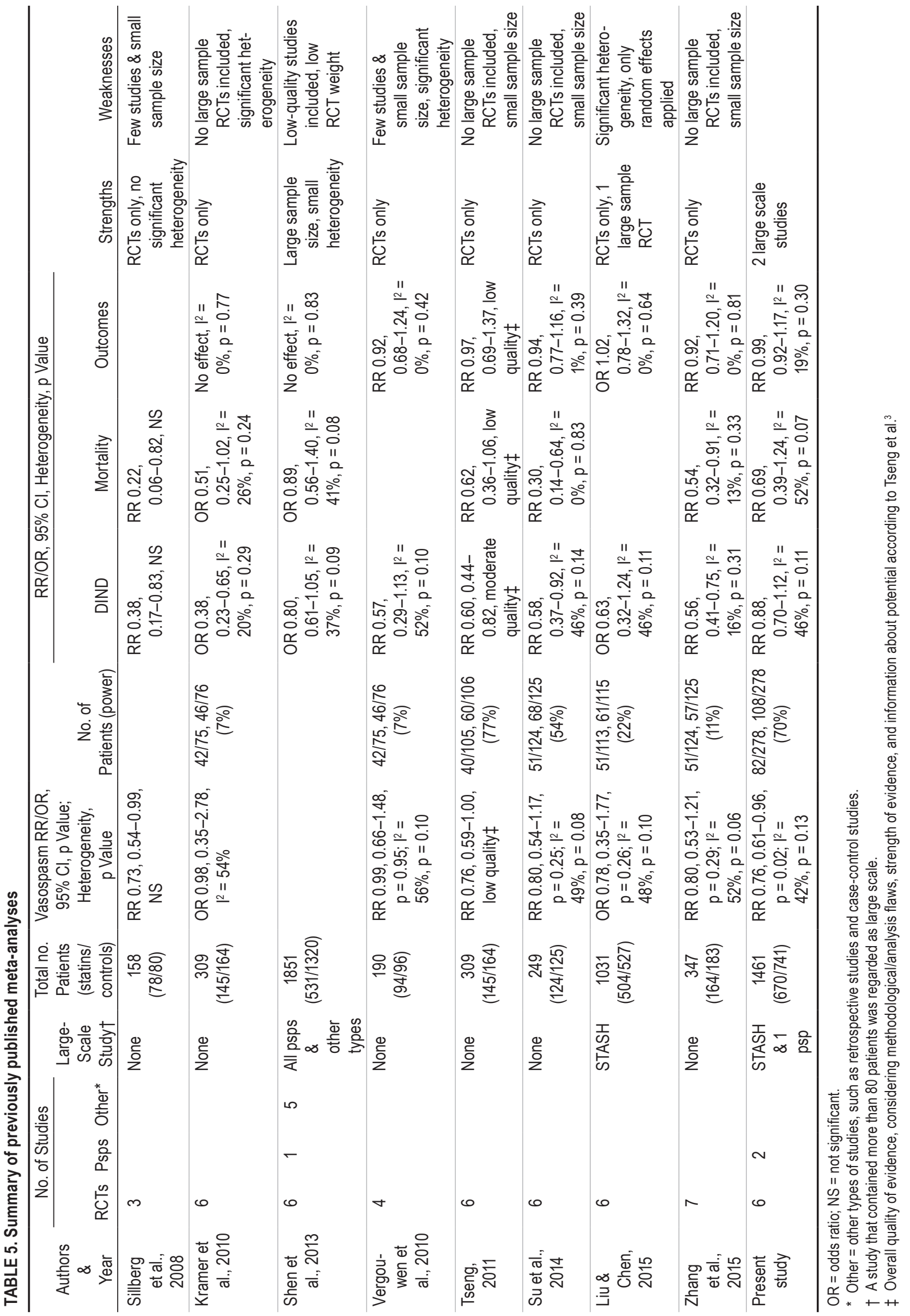


not improved and mortality rate was not reduced..$^{20,31,38,47}$ Vasospasm is not the only cause of DIND. Regional hypoperfusion and oligemia frequently occurred in territory or patients without angiographic vasospasm, and other factors such as early brain injury, cortical spreading depression ischemia, cerebral autoregulatory failure, and microthrombosis have been reported to cause DIND., 3,9,19,27,30 Taken together, these findings support a relationship between vasospasm and DIND and show that clinical deterioration due to DIND is more than simply angiographic vasospasm, and our findings support this. ${ }^{29}$ Further research should focus on DIND and delayed cerebral infarction. ${ }^{27}$ The failure of statin treatment may be attributed to an aggravation of other risk factors, despite its pharmacological efficacy in treating vasospasm. For example, some studies have shown that statins may increase the risk of intracerebral hemorrhage and hemorrhagic stroke by lowering the cholesterol level. ${ }^{2,11}$ It remains to be investigated whether the effectiveness of statin treatment can be improved in combination with other therapies, such as $\mathrm{HHH}$ therapy to reduce cerebral autoregulatory failure. ${ }^{15}$ The pathophysiological mechanism of these ischemic deficits and the possible relationship between statins and other etiologies of DIND remain to be elucidated.

There are several potential limitations to our metaanalysis. First, the included studies were not all RCTs, which may have enhanced the methodological heterogeneity. However, there are not enough published studies assessing DIND and delayed cerebral infarction to avoid heterogeneity altogether. Finally, substantial differences in the study design among RCTs, including differences in the treatment and outcome evaluation, were unavoidable, which may account for the heterogeneity between RCTs according to the subgroup analysis.

\section{Conclusions}

Statin treatment significantly reduced vasospasm but failed to reduce DIND, delayed cerebral infarction, or mortality rate. The outcome following aneurysmal SAH was also not improved by statin treatment. Further research should focus on DIND rather than simply on angiographic vasospasm and how statins influence DIND.

\section{Acknowledgments}

This study was supported by a grant from the National Natural Science Foundation of China (no. 81501065) and a grant from Zhejiang Provincial Natural Science Foundation (no. LY16H090004). We would like to thank Professor Shen Yi from Zhejiang University School of Public Health for his critical statistical review and analysis of this manuscript.

\section{References}

1. ACROSS Group: Epidemiology of aneurysmal subarachnoid hemorrhage in Australia and New Zealand: incidence and case fatality from the Australasian Cooperative Research on Subarachnoid Hemorrhage Study (ACROSS). Stroke 31:1843-1850, 2000

2. Amarenco P, Bogousslavsky J, Callahan A III, Goldstein LB, Hennerici M, Rudolph AE, et al: High-dose atorvastatin after stroke or transient ischemic attack. N Engl J Med 355:549559,2006
3. Budohoski KP, Czosnyka M, Smielewski P, Kasprowicz M, Helmy A, Bulters D, et al: Impairment of cerebral autoregulation predicts delayed cerebral ischemia after subarachnoid hemorrhage: a prospective observational study. Stroke 43:3230-3237, 2012

4. Chen J, Zhang ZG, Li Y, Wang Y, Wang L, Jiang H, et al: Statins induce angiogenesis, neurogenesis, and synaptogenesis after stroke. Ann Neurol 53:743-751, 2003

5. Chou SH, Smith EE, Badjatia N, Nogueira RG, Sims JR II, Ogilvy CS, et al: A randomized, double-blind, placebo-controlled pilot study of simvastatin in aneurysmal subarachnoid hemorrhage. Stroke 39:2891-2893, 2008

6. Crobeddu E, Mittal MK, Dupont S, Wijdicks EF, Lanzino G, Rabinstein AA: Predicting the lack of development of delayed cerebral ischemia after aneurysmal subarachnoid hemorrhage. Stroke 43:697-701, 2012

7. Diringer MN, Dhar R, Zazulia AR: Randomized controlled trial of the cerebrovascular hemodynamic effects of simvastatin in statin naïve patients with acute subarachnoid hemorrhage. Neurocrit Care 21:S200, 2014 (Abstract)

8. Endres M: Statins and stroke. J Cereb Blood Flow Metab 25:1093-1110, 2005

9. Frontera JA, Fernandez A, Schmidt JM, Claassen J, Wartenberg KE, Badjatia N, et al: Defining vasospasm after subarachnoid hemorrhage: what is the most clinically relevant definition? Stroke 40:1963-1968, 2009

10. Garg K, Sinha S, Kale SS, Chandra PS, Suri A, Singh MM, et al: Role of simvastatin in prevention of vasospasm and improving functional outcome after aneurysmal sub-arachnoid hemorrhage: a prospective, randomized, double-blind, placebo-controlled pilot trial. Br J Neurosurg 27:181-186, 2013

11. Goldstein MR, Mascitelli L, Pezzetta F: Hemorrhagic stroke in the Stroke Prevention by Aggressive Reduction in Cholesterol Levels study. Neurology 72:1448-1449, 2009

12. Hijdra A, Van Gijn J, Stefanko S, Van Dongen KJ, Vermeulen M, Van Crevel H: Delayed cerebral ischemia after aneurysmal subarachnoid hemorrhage: clinicoanatomic correlations. Neurology 36:329-333, 1986

13. Kirkpatrick PJ, Turner CL, Smith C, Hutchinson PJ, Murray GD: Simvastatin in aneurysmal subarachnoid haemorrhage (STASH): a multicentre randomised phase 3 trial. Lancet Neurol 13:666-675, 2014

14. Knuckey NW, Fox RA, Surveyor I, Stokes BA: Early cerebral blood flow and computerized tomography in predicting ischemia after cerebral aneurysm rupture. J Neurosurg 62: $850-855,1985$

15. Kosnik EJ, Hunt WE: Postoperative hypertension in the management of patients with intracranial arterial aneurysms. J Neurosurg 45:148-154, 1976

16. Kramer AH, Fletcher JJ: Statins in the management of patients with aneurysmal subarachnoid hemorrhage: a systematic review and meta-analysis. Neurocrit Care 12:285-296, 2010

17. Liu J, Chen Q: Effect of statins treatment for patients with aneurysmal subarachnoid hemorrhage: a systematic review and meta-analysis of observational studies and randomized controlled trials. Int J Clin Exp Med 8:7198-7208, 2015

18. Lynch JR, Wang H, McGirt MJ, Floyd J, Friedman AH, Coon AL, et al: Simvastatin reduces vasospasm after aneurysmal subarachnoid hemorrhage: results of a pilot randomized clinical trial. Stroke 36:2024-2026, 2005

19. Macdonald RL: Delayed neurological deterioration after subarachnoid haemorrhage. Nat Rev Neurol 10:44-58, 2014

20. Macdonald RL, Higashida RT, Keller E, Mayer SA, Molyneux A, Raabe A, et al: Clazosentan, an endothelin receptor antagonist, in patients with aneurysmal subarachnoid haemorrhage undergoing surgical clipping: a randomised, doubleblind, placebo-controlled phase 3 trial (CONSCIOUS-2). Lancet Neurol 10:618-625, 2011 
21. Macedo S, Siqueira CM, Siqueira S, Bello Y, Dias L: Effects of simvastatin in prevention of vasospasm in non-traumatic subarachnoid hemorrhage (preliminary data). Neurocrit Care 13:S213, 2010 (Abstract)

22. McGirt MJ, Blessing R, Alexander MJ, Nimjee SM, Woodworth GF, Friedman AH, et al: Risk of cerebral vasospasm after subarachnoid hemorrhage reduced by statin therapy: A multivariate analysis of an institutional experience. J Neurosurg 105:671-674, 2006

23. McGirt MJ, Garces Ambrossi GL, Huang J, Tamargo RJ: Simvastatin for the prevention of symptomatic cerebral vasospasm following aneurysmal subarachnoid hemorrhage: a single-institution prospective cohort study. J Neurosurg 110:968-974, 2009

24. McGirt MJ, Lynch JR, Parra A, Sheng H, Pearlstein RD, Laskowitz DT, et al: Simvastatin increases endothelial nitric oxide synthase and ameliorates cerebral vasospasm resulting from subarachnoid hemorrhage. Stroke 33:2950-2956, 2002

25. Nikitina E, Kawashima A, Takahashi M, Zhang ZD, Shang $\mathrm{X}$, Ai J, et al: Alteration in voltage-dependent calcium channels in dog basilar artery after subarachnoid hemorrhage. Laboratory investigation. J Neurosurg 113:870-880, 2010

26. Rabinstein AA, Friedman JA, Weigand SD, McClelland RL, Fulgham JR, Manno EM, et al: Predictors of cerebral infarction in aneurysmal subarachnoid hemorrhage. Stroke 35:1862-1866, 2004

27. Rowland MJ, Hadjipavlou G, Kelly M, Westbrook J, Pattinson KT: Delayed cerebral ischaemia after subarachnoid haemorrhage: looking beyond vasospasm. Br J Anaesth 109:315-329, 2012

28. Sabri M, Ai J, Marsden PA, Macdonald RL: Simvastatin recouples dysfunctional endothelial nitric oxide synthase in experimental subarachnoid hemorrhage. PLoS One 6:e17062, 2011

29. Sánchez-Porras R, Zheng Z, Santos E, Schöll M, Unterberg AW, Sakowitz OW: The role of spreading depolarization in subarachnoid hemorrhage. Eur J Neurol 20:1121-1127, 2013

30. Sarrafzadeh AS, Vajkoczy P, Bijlenga P, Schaller K: Monitoring in neurointensive care-the challenge to detect delayed cerebral ischemia in high-grade aneurysmal SAH. Front Neurol 5:134, 2014

31. Shen J, Pan JW, Fan ZX, Xiong XX, Zhan RY: Dissociation of vasospasm-related morbidity and outcomes in patients with aneurysmal subarachnoid hemorrhage treated with clazosentan: a meta-analysis of randomized controlled trials. J Neurosurg 119:180-189, 2013

32. Shimamura N, Ohkuma H: Phenotypic transformation of smooth muscle in vasospasm after aneurysmal subarachnoid hemorrhage. Transl Stroke Res 5:357-364, 2014

33. Sillberg VA, Wells GA, Perry JJ: Do statins improve outcomes and reduce the incidence of vasospasm after aneurysmal subarachnoid hemorrhage: a meta-analysis. Stroke 39:2622-2626, 2008

34. Su SH, Xu W, Hai J, Wu YF, Yu F: Effects of statins-use for patients with aneurysmal subarachnoid hemorrhage: a metaanalysis of randomized controlled trials. Sci Rep 4:4573, 2014

35. Sudlow CL, Warlow CP: Comparable studies of the incidence of stroke and its pathological types: results from an international collaboration. Stroke 28:491-499, 1997

36. Tseng MY: Summary of evidence on immediate statins therapy following aneurysmal subarachnoid hemorrhage. Neurocrit Care 15:298-301, 2011

37. Tseng MY, Czosnyka M, Richards H, Pickard JD, Kirkpatrick PJ: Effects of acute treatment with pravastatin on cerebral vasospasm, autoregulation, and delayed ischemic deficits after aneurysmal subarachnoid hemorrhage: a phase II randomized placebo-controlled trial. Stroke 36:1627-1632, 2005
38. Vajkoczy P, Meyer B, Weidauer S, Raabe A, Thome C, Ringel F, et al: Clazosentan (AXV-034343), a selective endothelin A receptor antagonist, in the prevention of cerebral vasospasm following severe aneurysmal subarachnoid hemorrhage: results of a randomized, double-blind, placebo-controlled, multicenter phase IIa study. J Neurosurg 103:9-17, 2005

39. van Gijn J, Kerr RS, Rinkel GJ: Subarachnoid haemorrhage. Lancet 369:306-318, 2007

40. van Gijn J, Rinkel GJ: Subarachnoid haemorrhage: diagnosis, causes and management. Brain 124:249-278, 2001

41. Vergouwen MD, de Haan RJ, Vermeulen M, Roos YB: Effect of statin treatment on vasospasm, delayed cerebral ischemia, and functional outcome in patients with aneurysmal subarachnoid hemorrhage: a systematic review and metaanalysis update. Stroke 41:e47-e52, 2010

42. Vergouwen MD, Meijers JC, Geskus RB, Coert BA, Horn J, Stroes ES, et al: Biologic effects of simvastatin in patients with aneurysmal subarachnoid hemorrhage: a double-blind, placebo-controlled randomized trial. J Cereb Blood Flow Metab 29:1444-1453, 2009

43. Vergouwen MD, Vermeulen M, van Gijn J, Rinkel GJ, Wijdicks EF, Muizelaar JP, et al: Definition of delayed cerebral ischemia after aneurysmal subarachnoid hemorrhage as an outcome event in clinical trials and observational studies: proposal of a multidisciplinary research group. Stroke 41:2391-2395, 2010

44. Wong GK, Chan DY, Siu DY, Zee BC, Poon WS, Chan MT, et al: High-dose simvastatin for aneurysmal subarachnoid hemorrhage: multicenter randomized controlled doubleblinded clinical trial. Stroke 46:382-388, 2015

45. Wong GK, Wong A, Zee BC, Poon WS, Chan MT, Gin T, et al: Cognitive outcome in acute simvastatin treatment for aneurysmal subarachnoid hemorrhage: A propensity matched analysis. J Neurol Sci 358:58-61, 2015

46. Woo SW, Kim JH, Kang HI, Kim DR, Moon BG, Kim JS: High-dose simvastatin is effective in preventing cerebral vasospasm after aneurysmal subarachnoid hemorrhage: a prospective cohort study in Korean patients. J Korean Neurosurg Soc 58:328-333, 2015

47. Young AM, Karri SK, Helmy A, Budohoski KP, Kirollos RW, Bulters DO, et al: Pharmacologic management of subarachnoid hemorrhage. World Neurosurg 84:28-35, 2015

48. Zhang BF, Song JN, Wang J, Ma XD, Zhang ST, Zhao JJ, et al: Effect of statins on aneurysmal subarachnoid hemorrhage: a meta-analysis of randomized controlled trials. Turk Neurosurg 25:850-857, 2015

\section{Disclosures}

The authors report no conflict of interest concerning the materials or methods used in this study or the findings specified in this paper.

\section{Author Contributions}

Conception and design: Zhan. Acquisition of data: Pan, Jiang, Weng. Analysis and interpretation of data: Jiang, Weng. Drafting the article: Shen, Huang, Zhu. Critically revising the article: Pan, Shen, Huang, Zhu. Reviewed submitted version of manuscript: Pan, Shen, Huang, Zhu. Statistical analysis: Shen, Huang, Zhu. Study supervision: Pan.

\section{Correspondence}

Jian-Wei Pan, Department of Neurosurgery, First Affiliated Hospital, School of Medicine, Zhejiang University, No. 79 Qingchun Rd., Hangzhou City 310003, Zhejiang Province, People's Republic of China. email: sjzju@163.com. 